\title{
Correction: Identification of conductive fractures in perched formations with the use of a reformed packer test without well logging
}

\author{
Po-Yi Chou ${ }^{1} \cdot$ Chun-Te Wang $^{1} \cdot$ Nian-Chang Wu ${ }^{1} \cdot$ Hsien-Chang Kao ${ }^{1,2}$ \\ Published online: 13 January 2021 \\ (C) Springer-Verlag GmbH Germany, part of Springer Nature 2021
}

Correction: Hydrogeology Journal (2020) 28:2275-2282

https://doi.org/10.1007/s10040-020-02170-6

The original article unfortunately missed out a critical reference that should be included with respect to Fig. 2. The appropriate corrections are as follows:

- A comprehensive caption for Fig. 2 is:

Fig. 2 Well-logging result of B107W-01 at Wanli (Central Geological Survey, 2018)

- The Acknowledgements section is expanded:

The authors are grateful for the technical support of Mr. ChanPeng Kang from Wilson Scientific, as well as the assistance and support given by the Central Geological Survey, Taiwan.

- An additional reference is provided:

Central Geological Survey (2018) Ground-water Monitoring Wells Construction and Rock Aquifer Hydraulic Properties Investigation in Northern Taiwan Mountainous Region and Groundwater Recharge Geologically Sensitive Area (1/4), Report commissioned by the Sinotech Engineering Consultants Inc.

Publisher's note Springer Nature remains neutral with regard to jurisdictional claims in published maps and institutional affiliations.

The online version of the original article can be found at https://doi.org/ 10.1007/s10040-020-02170-6

Po-Yi Chou

poyi.chou@sinotech.org.tw

Chun-Te Wang

justin@sinotech.org.tw

Nian-Chang Wu

kashemoto@sinotech.org.tw

Hsien-Chang Kao

hckao@sinotech.org.tw

1 Geotechnical Engineering Research Center, Sinotech Engineering Consultants, Inc., 280, Xinhu 2nd Rd., Neihu Dist, Taipei

City 11494, Taiwan

2 Department of Civil Engineering, National Taiwan University, 1, Sec. 4, Roosevelt Road, Taipei 10617, Taiwan 